\title{
The Impossibility of Egoism
}

The title of this chapter will remind some of you of - and stands in marked contrast with-the title of Thomas Nagel's The Possibility of Altruism (OUP, 1970). But Nagel was talking mainly of ethical or moral altruism, the idea that we have motive-entailing reason to help others, whereas I will be primarily concentrating not on ethical egoism but on psychological egoism, the idea that we always act in a self-interested way. Philosophers who have sought to defend moral altruism or morality in general have assumed that there are egoistic immoralists around and that a good enough philosophical argument might persuade them to be less immoral or even virtuous. I think Plato was making some such assumptions in the Republic, and those who have subsequently tried to philosophically explain why we should be moral have, I believe, accepted those same two basic assumptions. But I think both of them are mistaken, and though that still leaves plenty of challenges for moral philosophy and for moral individuals, those challenges will look quite different if it turns out that there are no total egoists and that philosophical argument cannot work on any person to the extent they are egoistic. In order to see why there cannot be any psychological egoists, we must first come to a clear or clearer understanding of what (psychological) egoism involves, and that will be the task that occupies us initially in what follows.

M. Slote, Between Psychology and Philosophy, Palgrave Studies in Comparative East-West Philosophy, https://doi.org/10.1007/978-3-030-22503-2_7 
When philosophers talk of egoism, they mainly have in mind a contrast between egoistic and altruistic motives, but I don't think we can fully understand, conceptually understand, what psychological egoism is or involves unless we see that the contrast between egoistic and altruistic motives doesn't cover, doesn't even begin to cover, the full range of (basic) human motives. Moreover, the term "altruism" is itself ambiguous, and we need to sort out that ambiguity before proceeding any further. Someone who thinks it is his duty to help others and who accordingly does just that acts conscientiously, and since their conscience is directing them to help others, they lack any egoistic or ulterior motive for what they do on behalf of other people. In some sense one can call such behavior and such motivation altruistic, but there is a narrower and, I think, more accurate sense of the term in which it is not. In the strictest or most accurate sense a person's motivation is altruistic if and only if their primary motive is to help others or some particular other, and when such helping is dictated and supported by a sense of obligation, it is not altruistic in the basic and colloquial sense that I am talking about. I shall use the term "altruistic" only of motivation that is basically altruistic - not based on conscience and not based on ulterior motives.

Of course, some philosophers, in fact many philosophers, have questioned whether there can be or actually is such a thing as altruistic human motivation in the above sense. Many of us have thought that Bishop Butler in his sermons settled that issue over three centuries ago, but in recent decades there has been a flurry of interest in the question of whether human altruism exists and many have thought they could show that it likely never does exist. I am not going to go through the entire philosophical thicket of such arguments here. I have done that in two recent books, A Sentimentalist Theory of the Mind (OUP, 2014) and Human Development and Human Life (Springerbriefs, 2016), and I don't really think it would be advisable (or even perhaps possible) to review those very lengthy discussions right here. Rather, I shall try to review what I take to be the philosophical import of those discussions by homing in on the highlights of what I just described as a philosophical thicket. I use that term advisedly or at least deliberately because I think much of the recent discussion muddies the waters and misses the main conceptual points of Butler's earlier arguments. But then it turns out that Butler himself conceived things more narrowly than I think we have reason to, and what I 
have to say on these topics will then lead us toward an explanation of why altruism is impossible. Let us proceed step by step.

I want first to consider a new way of arguing for psychological egoism that has been offered in recent decades (specific references can be found in the two books mentioned above). When people do favors for other people, they usually know that others will learn about what they have done, so some recent psychologists and philosophers have speculated that when one helps another person, it is very possible that one does so in order to avoid the criticisms or bad opinion of those who might find out if one didn't help. But such motivation, it is argued, is egoistic, and, it is further argued, it is very difficult to show that we ever help others without such background motives. This then, according to the argument, places the psychological possibility of altruism in serious doubt.

In my estimation, this sort of thinking goes wrong not only in the way it moves toward denying the possibility or likelihood of human altruism, but also and most importantly for our immediate purposes in the way it conceives psychological egoism. It treats the desire for the good opinion of others as an egoistic motive and that is in my opinion a deep mistake. I agree that it is possible to view the desire for the esteem or approval of others as a widespread human motive, even as a basic motive in human psychology. That is precisely A. H. Maslow's view in his famous Motivation and Personality (Harper and Row, 1954), but the fact that such a motive is basic or widespread doesn't entail that it is egoistic any more than it entails that it is altruistic. The desire for others' approval or esteem (and these are not quite the same thing) isn't altruistic because it involves no intrinsic desire to help others. Rather, it looks for what it can get from others, not for what it can do for others; and those who have argued that the desire to help others can be based (solely) in the desire for their approval (or non-disapproval) and that it in such cases is not altruistic are certainly right to that extent. But it is a mistake to suppose that this way of looking at or thinking about human attempts to help others tends to support psychological egoism. That is because the basic desire for others' approval is definitely not egoistic.

Let me contrast two cases of the desire for approval/esteem. In the first case one knows that one won't get a promotion and a higher salary unless one is popular or at least not disliked in one's company/firm. One then very cautiously and self-interestedly acts to ensure that one isn't disliked and/or that people in the company/firm think well of one, and if such is the case, one's motivation, one's desire for the esteem of others, is clearly 
self-interested/egoistic. But, as Maslow amply indicated and commonsense also suggests, the desire for the esteem of others is very often (perhaps in the majority of cases) not like this. The desire for the esteem of others has nothing to do with gaining (further) benefits for oneself like a higher salary or a corner office; rather, one just doesn't want people to dislike one or to think poorly of one. This is what Maslow meant by saying we have a basic desire to be esteemed (or approved or liked) by others. In our psychology this motive simply isn't necessarily or even usually tied to further goals or ulterior motives in the way involved in the case of the person who wants a promotion and more money; and when it isn't, there is nothing egoistic about the motive. Wanting more money is (in most cases) egoistic, and when the desire for others to like or approve of one is grounded (solely) in that motive, it is certainly operating under the aegis of egoism and is not merely non-altruistic. But an intrinsic desire to be liked will not count as egoistic in this way, and in fact there is nothing egoistic at all about it.

Now a natural counterargument can be given at this point. It can be said that in the case of the so-called intrinsic or basic desire for others to like or esteem one, one will be pleased if one gains their esteem and at least somewhat unhappy if one does not. Doesn't that involve an egoistic element or psychological grounding? Certainly not. The compassionate person gains pleasure from helping others, but needn't be helping others simply in order to get that pleasure. As Butler essentially taught us, one only gets the pleasure in such cases if one independently wants to see others happy or happier. The attainment of that more basic goal gives one pleasure-one is gaining what one wants (for another person), but one's desire to help the other person or to see them helped is psychologically fundamental in supposed cases of altruistic compassion, and the fact that one is pleased when that goal is attained or unhappy if it is not, only shows how much one cares and cares altruistically about the other person or persons. The pleasure of helping isn't the goal in such cases but only the result, even the anticipated result, of one's fundamental desire to help, and even if one can wonder whether humans are ever motivated by such fundamental altruism, there is no reason to hold that the pleasure received by any such altruistic person when they succeed in helping others really shows them as egoistic.

But the same considerations transpose to the case of wanting others to like or esteem one. The pleasure someone feels when they know or believe they are liked or esteemed arguably only shows how much independent importance they place on being liked or esteemed. It does nothing to 
show that such a motive is egoistic. Butler saw all this centuries ago, and we shouldn't forget the points that he was the first to make and that I have just been summarizing. The arguments just given tend toward the conclusion, then, that the desire to be liked (or esteemed or approved or, for that matter, loved) is neither altruistic nor egoistic. For convenience, let's call such motives neutral motives. Butler was the first to see the possibility of such motives, but he didn't invoke the idea of neutral motives as a separate category of human motivation because he didn't see the large and variegated place such motives have in our overall human psychology. He recognized certain motives, like malice, revenge, and curiosity/inquisitiveness, as neither egoistic nor altruistic, but seems to have seen this category as somewhat exceptional within human psychology, and I hope to show you that a wide range of human motives, perhaps even most human motivation, is neutral rather than either egoistic or altruistic.

Butler most famously argued that malice and revenge are not egoistic (obviously they are not altruistic), and in order to do so he mentioned some of the considerations or arguments I have brought out above. But malice and revenge are in an important sense negative-they seek the suffering or death of others, and the fact of this negativity may have been part of what prevented him from calling such motives neutral. Still, his point that people acting from the motive of revenge will seek the suffering or destruction of others even at a considerable cost to themselves (cutting off their nose to spite their face) played an important part in his attempt to persuade people that malice and revenge are not egoistic. He then compared the motivational structure of compassion and benevolence with that of malice and revenge in order to show that the former too are not egoistic and $c a n$ be considered altruistic in a way the latter obviously are not.

Butler also saw that at least one other human motive is neither altruistic nor egoistic: inquisitiveness or curiosity (we needn't distinguish them). But he gives no explanation of why it isn't egoistic, he just says it isn't; and I think we ought to focus more than Butler did on curiosity if we want a complete or more complete picture of why both revenge/malice and the desire to be liked/esteemed/approved are not egoistic motives and, for obvious reasons, therefore, neither egoistic nor altruistic. Understanding curiosity or inquisitiveness better will help us see how widely and deeply and variously neutral motivation occurs in human lives.

Curiosity can serve the purpose or purposes of human or animal survival. But there have been studies showing that animals can be curious independently of their desire for food or survival. Exploratory behavior 
serves egoistic purposes, but doesn't have to, and human curiosity runs more deeply or more broadly than such purposes. A child can be curious about the moon or about ancient Egypt having seen pictures of the pyramids, and adults can be similarly curious, but none of this has to be in the service of other (more basic) needs or desires. As Aristotle tells us in the Metaphysics, man (sic) by nature desires to know. Curiosity is built into our human framework and built in in a way that doesn't require direct psychological connection to survival needs and the like. This much is common sense. But think what it implies. If I want to learn about my surroundings because I think I need to do so in order to survive, then my desire to know is egoistic. But if I want to know about things out of sheer or basic curiosity, ulterior motives are out of the picture and, as Butler saw, there is no reason to characterize the motivation involved as egoistic.

Indeed, I think we can offer a deeper explanation of why such motivation isn't egoistic than anything Butler gives us. When I want to know about ancient Egypt or the moon for its own sake, I place a certain importance on finding out about Egypt or the moon. We can even say that I thereby place a certain intrinsic importance on, say, the moon. It becomes important to me independently of whether it can provide me with good things other than the sheer knowing more about it. I would say that this fact of attributed importance is basic and essential to the non-egoistic character of the curiosity about the moon or of curiosity more generally. A motive isn't egoistic if it involves one in placing intrinsic importance (to oneself) on something outside of oneself (or larger than oneself). To be curious for survival purposes places curiosity in the service of the self and places no intrinsic or independent (of oneself) importance on learning what one seeks to learn. But ordinary curiosity is not instrumental like that and counts as non-egoistic on that basis.

The same considerations apply to revenge. Although the vengeful person might not like and would be surprised perhaps to hear this, their desire for revenge ascribes a certain intrinsic importance in their life to the person they want to take revenge against. If one were really egoistic, one wouldn't care about (what happens to) a person one hates: one would act against them if that would serve one's other purposes, but one wouldn't care for its own sake that they should suffer or be destroyed. Yet this latter is part of the psychology of revenge and that shows the non-egoistic character of ordinary revenge. It places too great an intrinsic importance on what happens to another person to count as egoistic - the egoistic person intrinsically cares only about what happens to her- or himself. 
I am saying, then, that a motive counts as egoistic if and only if it doesn't place intrinsic importance on things or persons outside of oneself. Butler never mentions this general criterion, but it subsumes what he does say while at the same time offering what I believe to be a deeper explanation of what he was arguing for. (We will see the full extent of this later in the chapter.) We have reason, then, now to regard the desire for esteem, etc., malice and revenge, curiosity, and compassion as non-egoistic, even if it is only the last mentioned that can be accounted altruistic. It is time now to see just how broadly the category of neutral motives extends-this will be relevant to our main question concerning the possibility of egoism.

\section{2}

Malice/revenge, inquisitiveness, and the desire for others' esteem, and so on, can all be conceptualized as neutral motives, but only the last of these is specifically spoken of in the work of A. H. Maslow. Maslow thinks the desire for esteem and the desire for love are basic to us humans, but he doesn't seem worried about the issues surrounding psychological egoism and so he never says that these basic desires are not egoistic (indeed he seems to imply that they are egoistic in some of his later writings). But we can, I hope, agree that these desires are neither egoistic nor altruistic. Given the intrinsic importance it places on what is outside the self, we can see this with the desire for esteem or being liked, and the same considerations also extend to the desire for love. However, this may be less obvious in this last case because the desire for love can easily be confused with the capacity for love, and the latter may seem altruistic. But there is an ambiguity here. The capacity for love might refer to the desire for love or to one's capacity for loving others, and it is far from conceptually or humanly clear that someone who desires the love of others will necessarily be capable or desirous of loving them back.

Children need and want their parents' love and become angry and even anti-social if they are not loved. But the love of one's parents may not be there from the start and may depend on whether the parents start a cycle of love by first loving the child. There is a lot of evidence around that children will not love their parents if their parents show them no love, so the desire for love and the capacity for and actuality of loving others are separable phenomena. This means, I think, that it makes sense to see loving others as altruistic but the desire for others' love as non-altruistic, but, more importantly, also as non-egoistic. Children or even babies who 
want their mother's or their parents' love place a great importance on their mother or their parents, and this is arguably not importance based on egoistic considerations. Even if a child is given every material or physical comfort, they will be angry and likely become anti-social if this was done in an emotionally antiseptic way. The need for love then shows the importance of the other to us, and this is not egoistic. So I hope we can go forward recognizing both the desire for esteem and the desire for love, desires Maslow thinks of as basic to humanity, as non-egoistic and neutral.

But Maslow mentions other desires as also basic and at least one of them, the desire to belong, also seems to be neutral in our sense. The desire to belong is or involves the desire to be accepted, and the latter also and obviously counts as non-egoistic if the desire for esteem is. Maslow also and perhaps most famously talks of a desire for self-actualization that he considers to be the highest of all human motives. However, I don't want to consider the hierarchical aspects of Maslow's view of this motive and prefer to bring his discussion down to earth a bit by speaking not of the desire for self-actualization, but of the desire for competence and/or mastery. Such a desire or range of desires is arguably basic to human beings: we want to be competent in and about the world, to master certain skills or tasks, somewhat independently of survival needs or our physical appetites. One sees the independent or basic desire for competence and mastery, for example, in babies and young children: consider, for example, the child who doesn't want his mother to feed him anymore and who strongly and vehemently prefers to (learn to) feed himself.

But the range of neutral motives extends well beyond any motives described or suggested by Maslow. Human beings, like many animals and even some reptiles, like to be around conspecifics. This isn't egoistic, even if it carries benefits, because, again, the craving for human company places an importance on others (sometimes any old others) independently of anything (else) they can do for one. Then, too, there is the desire to be like others, to imitate them. Again, one sees that in children, even in babies, and the desire to imitate places an importance on other people, so in our terms and for the reasons that have been offered here, this desire is not egoistic but, rather, neutral.

Everything I have said so far leaves intact the idea that certain basic human desires are egoistic rather than neutral or altruistic. Appetitive desires are egoistic, for example, though one has to be careful in saying this because some philosophers might want to say that a desire isn't egoistic unless it specifically and consciously aims and solely aims at the welfare 
of the person whose desire it is. But in conceptual and historical terms this is a much too demanding criterion of egoistic status. Since children and animals often grab food without thinking in high-falutin' terms about their own welfare or well-being, such a criterion would much too easily undercut the thesis of universal psychological egoism. A motive can be altruistic even if it doesn't self-consciously aim at the other person's wellbeing: as, for example, when one seeks to relieve pain without having the thought that it is good for someone to have their pain relieved. By the same token the desire for food or sex or (a new egoistic motive) comfort is egoistic (in standard cases) even if it isn't accompanied by or based on any thinking about what would make one's life go better. But things are about to become more interesting.

We standardly think of egoism as associated with and based on desires that bring pleasure or satisfaction, for example, desires for food, drink, or sex-and let us assume that we are not making the mistake of thinking of the desire for knowledge as egoistic because the person who desires such knowledge will get some pleasure from its attainment. We think that the desire for food is egoistic because it involves and is based on a desire for one's own pleasure or reduced discomfort or pain. But arguably that is not the whole story, and when the whole or a larger story is told, we will see that neutral motivation is in surprising ways involved in those very desires that philosophers commonly regard as strictly or purely and obviously egoistic. Let us approach these issues through Bishop Butler and his critics. In his Fifteen Sermons, Butler says that “...all particular appetites and passions are directed towards external things themselves, distinct from the pleasure arising from them...." However, in their recent review and critique of Butler's moral psychology, Elliott Sober and David Sloan Wilson take issue with this idea. Butler's idea is supposed to contradict and work against psychological hedonism, but Sober and Wilson argue that Butler's idea is mistaken if we (standardly) want food only in order to get pleasure from eating it. Even if the desire for pleasure requires a desire for something other than pleasure, they think the latter may function as a (mere) means to the pleasure, and this would preserve hedonism against what Butler has to say against it.

\footnotetext{
${ }^{1}$ Joseph Butler, Fifteen Sermons upon Human Nature, reprinted in L. A. Selby-Bigge, ed., British Moralists: Being Selections from Writers Principally of the Eighteenth Century, NY: Dover Books, 1965, vol. 1, see especially p. 227.
} 
But there is much more to Butler's anti-hedonistic viewpoint than Sober and Wilson recognize, even if Butler himself doesn't present things in a way that clearly counteracts what Sober and Wilson say in defense of psychological hedonism. Sober and Wilson state: "[h]edonism says that people want food because they want pleasure (and believe that food will bring them pleasure). Butler ... concludes that this causal claim is false, but for no good reason." 2 And they are right to claim as they do that Butler never specifically argues against that causal claim. Rather, his view seems in some way simply to assume that it is false. But I am inclined to think Butler is actually right in this matter. He hasn't, however, stated his case as well as he might have, and I propose to bring out the strengths in Butler's position more fully and/or intuitively than he himself does. The idea or conclusion quoted from Butler above embodies an insight that has eluded Sober and Wilson (and a lot of others including my earlier self), so let me expatiate on what I take that insight to be.

Astronauts have sometimes criticized the food that is provided for them in space. In particular, they have complained that what is squeezed out of a tube, even if it has beef or chicken flavor, doesn't allow for ordinary chewing, and their complaint suggests or more than suggests that we want more than flavor out of food, that we want to chew our food. We are not just accustomed to chewing but like to chew and miss chewing when we can't do it. (There are all kinds of things we are accustomed to but don't at all miss when they no longer occur.) All this would mean that chewing and the fact that it is food that is being chewed has an importance for us independently of flavor, that we want to be in a certain (variable but ongoing) relation to food and have less pleasure when this isn't occurring. And don't say that this merely shows that we want the pleasure of chewing, not the chewing itself. That is no more plausible or forceful as an objection than the idea that when we seek knowledge, it is the pleasure of knowing rather than the knowing that is our primary goal. We have already seen what is wrong with that idea and Butler presumably sees that it would be a mistake to make a similar objection to what he says about our desires for external things like food. The desire to chew food (which Butler never mentions) is a desire for an external thing not based on any hedonistic desire for pleasure even if the chewing brings pleasure; and though I don't want to consider Butler's very general claim, as expressed above, about

\footnotetext{
${ }^{2}$ See their Unto Others: The Evolution and Psychology of Unselfish Behavior, Cambridge: Harvard University Press, 1998, pp. 276-281.
} 
what we always want, that claim is nicely and persuasively illustrated in the instance of food and the pleasure of eating (and chewing). Moreover, eating comes as close as it is possible to come to a desire that is purely egoistic, so if even here there is something other than egoism operating in our minds, the case for universal psychological egoism will be undermined on what is normally considered its most favorable terrain.

However, I have not yet directly addressed the issue of egoism with respect to the particular example of eating and chewing. I have supported Butler in his contention that we are after more than pleasure in such instances, but this only undercuts hedonism, and there are forms of egoism that are compatible with the denial of hedonism: forms, for example, that specify other things than pleasure as basically good for us and that claim that we are (ultimately) always and only seeking one or another kind of thing that is good for us. In fact, Butler doesn't seem to regard his refutation of hedonism as likewise a refutation of psychological egoism, but I think that in fact it is or leads to both of these things. To treat food and the chewing of it as important is to treat something outside ourselves as important to us. We may want the pleasure of eating and that is certainly internal to us and allows for an egoistic motivational interpretation. But if we also want food because only with food can we have the pleasure of chewing the food, then we are well on our way to the denial of egoism.

Now someone might object that as I have just put the matter, the desire for food is a desire for a certain internal pleasure, the pleasure of chewing it; and this might be taken to mean that we still have no objection here and at the core of supposedly egoistic motivation to the general thesis of egoism. But it all depends, in fact, on how we understand or explain the pleasure of chewing. Certain tastes, like the taste of pretzels or of ice cream, are inherently pleasurable to most of us. These things taste good, but chewing doesn't provide its own distinctive good taste or tastes. Instead, it is the act of chewing (food) that gives us pleasure, rather than some pleasure like a good taste that we can independently associate with chewing. We get pleasure from chewing rather than chewing in order to attain some independently specifiable good. The analogy with the pleasure one gets from satisfying curiosity or helping others seems strong enough to suggest, therefore, that the desire for food and for chewing food (and this is just one prime example) are not so much desires for some state of oneself as desires to be in a certain intrinsically valued relation to something outside oneself. Butler may not have seen that the desire to eat solid food is not purely egoistic, but he did see that we have desires for external things at 
least somewhat independently of (that are not entirely based in) our desires for pleasure, and this insight leads in the way indicated in our arguments here toward the conclusion that psychological egoism is false and false in regard to that area of human life, the appetites, that is traditionally thought to provide the paradigm of egoistic motivation.

We can go further. We have already seen that curiosity and exploration in its name are not egoistic because they place an importance on something outside the self. Well, it seems to me that the desire to chew is somewhat akin to curiosity and the desire to explore. The example may be mundane or prosaic, but when we chew, we are in effect exploring the insides of the food we are eating, and I don't think that the connection is purely accidental or gratuitous. When we eat we are finding out, for example, about the consistency of some item of food we are taking into our mouth, and I think it makes a certain sense to suppose that when the astronauts (explorers that they are) complain about being unable to chew, they aren't just complaining because they aren't accustomed to the kind of eating they must do in space. There is a certain relation to their food that is absent in space and that they miss having, even if what they are given through a tube is full of flavor. This gives normal food itself a certain intrinsic importance for them, and I think that importance at least partly relates to (a perhaps prosaic kind of) non-egoistic curiosity and a nonegoistic desire to explore that are, after all, qualities we paradigmatically associate with astronauts.

What has just been said about eating can be said perhaps more forcefully about other examples of supposedly egoistic activities and pleasures, and perhaps some readers will need to brace themselves before reading what I say next. Making love brings its distinctive pleasures, but fellatio and cunnilingus are enjoyable in part because they allow of a certain non-egoistic exploration of and new forms of acquaintance with the male or female genitals and with a human body more generally. ${ }^{3}$ The list could go on, but

\footnotetext{
${ }^{3}$ According to Kant in his Lectures on Ethics (and many others), sexual desire is just a matter of egoistically wanting to use another's body for purposes of one's own pleasure. But following up on what Butler says about wanting things in the world, it seems to me that sexual desire involves much more than that. For purposes of comparison, let's consider the desire for revenge. That desire pays a certain unwitting compliment to the person one wants to take revenge on, treats them as important to one in a way the revenge taker might find it embarrassing to have to acknowledge; and such attributed importance to something outside of oneself takes us beyond sheer egoism. I think sexual attraction pays a similar compliment to another person's body (as suffused by their personality). It treats their (beautiful or mysterious) looks or the (graceful or sensuous) way they move as important to one in a way that
} 
what we have been seeing here is how neutral motivation not only has a wide variety of instances in ordinary life, but also invades or pervades areas that are normally considered purely egoistic. And talk of variety in fact understates the matter. When you consider that the desire for love/esteem, curiosity, the desire for competence/mastery, the desire for revenge, the desire to belong, the desire to be around others, and the desire to be like others are all neutral, you can see that neutral motivation pervades all our lives. ${ }^{4}$ Psychological egoism is true of far less human motivation than even

makes one want to take one's sexual pleasure with them and not, say, with someone one is less attracted to. Indeed, the attraction makes it easier to obtain greater pleasure with that particular person and so involves more than the sheer egoistic desire for pleasure. One doesn't want their body or find it attractive because (one thinks) it will be easier to get pleasure with it, but rather it is easier to get pleasure with that body (and that person) because one wants and is attracted to it (and them). This is parallel with what we find with compassion. The compassionate person gets pleasure from helping those in need because they want to help them, rather than helping them because they want to obtain the pleasure of doing so; and this gives us a basis for arguing that compassion is non-egoistic. We have just seen that the same distinction holds for sexual attraction and therefore indicates that sexual desire/appetite involves a substantially non-egoistic aspect or component. (I'll bet Butler knew all of this, but, given his role in the Anglican Church and the times he lived in, couldn't say it directly, having to confine his discussion to the vaguer idea of wanting "external things themselves.") Now what I have just said about sexual appetite and attraction goes beyond the ideas about non-egoistic sexual exploration that were defended in the main text, but I cannot forbear mentioning here, finally, that what I said above about sex and the desire to explore is anticipated in a non-philosophical way in John Donne's poem "To His Mistress Going to Bed." In it he speaks tenderly of her beauty and then apostrophizes it with the words "O my America! My new-found-land...."

${ }^{4}$ Neutral motivation attributes intrinsic importance (though not necessarily positive value) to things and/or people outside ourselves, and this is also true of altruistic motivation and, to a surprising extent, of our appetites. But this may mean that bringing things and people outside ourselves into our lives and doing so for non-egoistic reasons is what is most characteristic of human life considered as a whole. (For a full-scale discussion, see my Human Development and Human Life, Springerbriefs, 2016, Chap. 3.) This is a highly abstract overall characterization of human life or lives, and I have had colleagues wonder about whether doing this sort of thing is really philosophy. But Aristotle, Hobbes, Heidegger, and Sartre all sought in their different ways to characterize human life on the whole, and even if analytic philosophers haven't gone in for this sort of thing, it is still a long-standing enterprise within philosophy. I have just been trying to do the same thing as these others but on a basis that takes more account of what psychology as a discipline has recently taught us than, obviously, these other philosophers were able to do. I therefore hope that the broad picture of human life I have just (so briefly) described here is more realistic and accurate than what others have suggested in the past. Finally, let me suggest that our pervasive human tendency to reach out to things beyond ourselves and bring them into our lives may be further characterizable in terms of yin and yang. But exploring this possibility will have to wait for another occasion. 
defenders of altruism (like Butler, but also like Sober and Wilson) have recognized. (Sober and Wilson's criterion of egoistic motivation commits them to treating curiosity about the moon as egoistic.) We now need to see how these presumed facts bear on the possibility of totally egoistic people.

\section{3}

How does what we have been saying relate to the possibility of total psychological egoism on the part of some or many individuals? Well, the plethora of neutral motives raises questions about such a possibility that could not or would not be raised if we ignored or were ignorant of them. If the issue is just psychological egoism vs. psychological altruism (and Maslow seems to have seen things that way even if Butler clearly did not), then since altruism is somewhat infrequently attributable to human motives, one might well think that if there were a few more bad eggs among humanity, everyone would just be totally egoistic. It is much much more difficult to speculate in that direction if the thesis of possible egoism requires one to assume that a whole range of actual human motives, the neutral ones, would have to be otherwise if psychological egoism were to be realized as a possibility (either for one person or for people more generally). But let me now be more specific. Are there neutral motives that cannot fail to exist among human beings? If there are, then psychological egoism will be impossible for us and perhaps for any possible intelligent beings. But what do I have in mind here?

Well, a world of egoists or a single egoist requires the absence of any need/desire to belong, any desire to be loved or esteemed, any desire to be like or be with others, any desire for sheer competence, any desire to chew food rather than simply experience its flavor (or taste?). Such a world would be very different from our own, and it is difficult to believe that a race of humans or other creatures could have evolved in the absence of all such neutral motives. The cohesiveness of society depends on such motives and it doesn't seem possible for evolution to occur independently of social groupings. But still perhaps single individuals could exist in the absence of the above neutral motives even if the societies or groups they are part of or come from could not.

However, I don't actually think this would be possible. In my list of neutral motives above I omitted the neutral motive of inquisitiveness/curiosity, and I did that for a reason. I don't think societies or given individuals can 
exist without that motive, and if that is so, then total egoism is impossible both at the social (or species) level and at the individual level. But why should curiosity be so necessary? Why is intelligent human life unthinkable without the presence of curiosity? This requires some explaining.

The best way to approach this issue involves us in paying attention to the phenomenon of paying attention, involves us in focusing on the phenomenon of focusing. Sometimes when we focus on or pay attention to some object or event, we do so for instrumental, means-end reasons. We are looking for a scissors and are told there is one in the right hand corner of the kitchen counter, so we focus our attention on that right hand corner and, if our information is correct, find the scissors we need. But much more frequently we pay attention and/or focus without having some specific ulterior purpose for or in doing so. We hear a small noise to our left and focus our attention, our eyes in particular, in that direction because we are curious as to what made the noise. This kind of attention or focusing is going on practically all the time in any human being of almost any age. Neonates may not focus in this way, but maturational processes fairly quickly lead to such focusing, and for the very young and for adults this kind of focusing or paying attention is a mark of curiosity. Of course, when I pay (more) attention to a color that flashes across my field of vision, my paying of attention, my focusing on the color, say, is something that happens fairly automatically. And I may not know or at least think that I am paying attention or focusing, but still it is natural and colloquial to speak in this connection of the/an act of focusing or paying attention because at whatever level of non-self-consciousness, the focusing is something we want and choose to do.

This sort of thing is going on all the time: for example, I want to know what is happening over there to my left and I focus in that direction. And this wanting to know is in such frequent or constant instances a form of curiosity, a motive or motivation that is leading us to focus and pay attention in all kinds of ways all the time (not, of course, at every waking instant or while we are sleeping or going to sleep). We normally think of curiosity as a motive that leads us to find out specific things about specific areas of our environment or about facts of history, geography, or astronomy; and such curiosity is typically self-aware and expressed or manifested in very conscious and deliberate actions: like subscribing to or reading National Geographic. But my point is that the less self-conscious kind of attention paying is happening all the time and 
manifests our curiosity just as much but also much more deeply than what we do when we read an article about ancient Egypt or about modern Borneo.

If we didn't have a kind of basic and non-instrumental focusing curiosity, we would learn much less, perhaps very little, about the world. In the absence of focus and attention, the world would remain a blur, a "blooming, buzzing confusion" (in William James's famous words). And ordinary life would be impossible for us because ordinary life requires us to know all kinds of things that can be known only by focusing and/or paying attention and by doing so independently of specific instrumental purposes beyond the desire to know. Similar points also hold for one item on our original list of neutral motives (as given just above), the desire for competence. A baby is not going to learn about the world or learn to make their way successfully in their childhood world without some primal curiosity, but by the same token they won't be able to do what they need to do unless they have a desire for competence or mastery, a desire, for example and as I mentioned earlier, to eat on their own. The young child doesn't reason "my mother isn't going to feed me indefinitely so I had better learn to eat on my own if I want to survive and do well." And even if they did, that wouldn't lead them, as happens is most cases, to want to master eating on their own before their mother or care-giver shows any sign of wanting the child to do things on their own. No, the desire for competence is intrinsic to children rather than a matter of instrumental thinking. So more generally a child is not going to learn about the world or learn to make their way in the world without some primal curiosity and some primal desire for competence or mastery in the/their world, and these motivational tendencies need to continue in some force into later life if an individual is to meet their life's later instrumental/practical and epistemic challenges. Since both curiosity and the desire for competence are non-egoistic neutral motives, we can see that individuals cannot survive or thrive on egoistic motives (as it were, on bread) alone; and that is my reason for saying that psychological egoism is actually impossible for any individual. The psychopathic egoist actually needs to have some neutral motivation in order to survive and thrive in the world and in that case is not a psychological egoist. This gives the sense, adumbrated by the title of this chapter, in which egoism is impossible.

Moreover, and quite obviously, if all this is so then it makes no sense to try to argue some supposed (total) egoist out of their egoistic motivation. There is no such possible person to make that argument to. But still there are such things as egoistic motives, even if total egoism is impossible, and some people not only are more egoistically motivated than others but also 
are led by such motivation to do immoral things that others would not do. Doesn't it at least make sense to try to show such people that they would likely be better off if they were less egoistic, and if it does, isn't the main purpose of a book like the Republic or of articles on why we should be moral preserved as meaningful and worth pursuing? I don't necessarily think so.

The idea that one can persuade someone via argument to change their motivational ways is fraught with conceptual peril and let me say some things about this. The idea that such persuasion can be successful means that some largely egoistical people will change in motivation as a result of hearing/reading and being persuaded by certain arguments against egoism. But those arguments are typically of one of two kinds (sometimes these are combined). They either seek to show that egoism doesn't pay in self-interested terms or they seek to show that egoism fails of some other purpose that most people have, for example, the desire to be self-consistent or to be justified in one's behavior/actions. In the latter case one might try to persuade some egoist that although their egoism was mainly to their advantage, it left them self-inconsistent and subject to a charge of irrationality in a way they would be embarrassed to have to acknowledge. Or one might argue that their egoism simply left them unjustified in many of their actions and thereby subject to a charge of irrationality that they would not wish to be subject to. Let's examine these last two possibilities, starting with the idea of self-inconsistency.

It might be thought in particular that Kant's criticisms of immorality and egoism can draw on the idea that immoralists are self-inconsistent in order to offer an argument that might or ought to persuade immoral egoists to think and act differently. But that would be a mistake. Many people interpret Kant as saying that immorality involves a kind of inconsistency, but Kant never says that there is any inconsistency in (the will of) immoral people whose maxims of action don't accord with the Categorical Imperative. Rather, he says that if the maxim of one's action is to be morally acceptable, then willing it to be a universal law must be consistent with the having of that maxim. For example, it is immoral to be unwilling to help others in need because someone whose maxim involves such unwillingness cannot in all consistency at the same time also will that his maxim should be a universal law governing how people act. What is inconsistent for Kant, therefore, is not the will of an immoralist, but the combination of such a will with their willing the maxim of their will to become a universal law. So Kantian means cannot so readily be used to persuade 
the immoralist that they are inconsistent in their willing in a way that they would not want to be. Even granting that people want to think of themselves as not irrationally inconsistent, the Kantian argument doesn't effectively work against egoism in the terms just indicated.

This still leaves open the possibility that one might show the egoist that they are irrational in some other way, irrational, for example, because they are in some sense not justified in acting immorally. But even if one wants to be and think of oneself as being justified in one's actions, an argument against the immoralist might well fail of its purpose if it merely showed them that their actions are often unjustified. If it were still maintained that their actions served their egoistic interests better than always acting morally would, they might prefer to be unjustified all the way to the bank rather than become justified at the cost of giving up some of their happinessenhancing egoistic interests or desires. The matter is a delicate one, but our way of stating it might convince us that it is best to confront the egoist "head on." Rather than try to show them that they are irrational or unjustified, one might try to show them that their irrationality or lack of justification doesn't pay off in the egoistic terms - and we are thinking of people with a lot of egoistic motivation-that are obviously so important to them as the egoists that they are. Cutting to the chase in this way brings us back to the line of anti-egoism one finds in Plato and in the writings of many other subsequent philosophers stretching from his time to the present.

However, if we move in this direction, we have to face up to a major problem that was already discussed in Chap. 3. Motivational change is not an easy thing for or in a human being, and motivations, like beliefs, are typically beyond our ability to control them. If someone offers me a million dollars if I can believe, really believe, that there is no such place as Chicago, then I am not going to be able to collect on that offer even if I know and believe that it will be to my advantage if I can somehow come to believe there is no such place as Chicago. Belief isn't subject to our will in such cases and issues of egoistic benefit don't affect that fact. But all this is true not only of beliefs but also of emotions. If I am offered a million dollars if I can start loving, really loving, Charles Manson, then, again, I am not going to be able to collect.

Well, being moral and being egoistic are also matters of motivation, and Chap. 3 pointed out how problematic it would be to suppose that one could make someone morally virtuous if one could persuade them that they would be better off or happier if they were virtuous. Even if one were persuaded of this and, as a relatively egoistic person, wanted to become 
moral or more moral, the way forward with such a desire is totally unclear. Knowing or believing that one will be better off in self-interested terms if one is (more) virtuous, how does the selfish person, the relatively egoistic person, turn that desire into a reality? What can they do to make themselves into the kind of person they now, as a result of a philosophical argument, want to be? There are no pills one can take to transform one into a moral or caring person, and, as Chap. 3 mentioned, the idea of simply imitating some acknowledged moral exemplar doesn't indicate any sure or even likely path toward motivationally resembling that person. The desire to imitate and to become moral might motivate one's imitation of the actions of the virtuous person, but that motivation is very different from the motivation of the person one is imitating, a person who isn't trying via imitation to become moral but already is moral, a person who has characteristically caring motivations that we are assuming are now absent in the person who wants on egoistic grounds to become moral. The so-called law of exercise (spoken of in Chap. 3) might allow us to explain such a motivational change, but psychologists have been very reluctant to accept that law, and I am inclined to conclude, therefore, that philosophical arguments are not going to be very helping toward converting the largely egoistic person into a virtuous person, even arguments appealing to their desire for their own good. Chapter 3 noted ways in which motivational change can be brought about in people, ways in which people can be made or led to be more caring or, more generally, virtuous, but none of those ways involved the giving of a philosophical argument, and I am inclined to conclude that the attempt to persuade the largely egoistic individual to mend their ways is a lost cause. It may be true and true for the reasons offered in Chap. 6 that being totally immoral involves not being contented or happy in or with one's life. But this doesn't translate into any ability to effect moral change that philosophical argument would distinctively and helpfully possess.

One might think that there is some consolation here in the fact that at least there are no total egoists needing conversion to morality, but that would be a mistake. There are no total egoists because everyone, even the totally immoral moral monster, needs neutral motives like curiosity and the desire for competence, but those very motives ensure that the malicious person will develop the skills necessary to deliver on their malicious intentions. If anything, the fact that moral monsters are likely to have the skills that enable them to do great harm to others gives one all the more reason to wish that there was some way of philosophically persuading 
them to change. And this is all the more true, perhaps, because psychologists generally think there is no other less intellectual or therapeutic way to change such people for the morally better. So the fact that egoism is impossible and the reasons that lie behind that impossibility give no encouragement in the end to the philosophical enterprise of Plato's Republic and to other such efforts. We cannot change the totally immoral, cannot persuade them via philosophical arguments to become or be virtuous, and the only consolation we actually have, therefore, is the consolation, the bitter and perhaps mean-spirited consolation that we have described in Chap. 6: the consolation that the totally and unconvertible immoral are likely to have much less good lives than (we) ordinary people have.

But we need to move on. All the chapters of this book have mentioned and discussed important ways in which attention to psychological issues can help us to a better understanding of important philosophical issues. But one can draw out significant further implications of our previous discussion(s) for the connection between psychology and philosophy, and I want to do that in our next chapter.

Open Access This chapter is licensed under the terms of the Creative Commons Attribution 4.0 International License (http://creativecommons.org/licenses/ by $/ 4.0 /$ ), which permits use, sharing, adaptation, distribution and reproduction in any medium or format, as long as you give appropriate credit to the original author(s) and the source, provide a link to the Creative Commons licence and indicate if changes were made.

The images or other third party material in this chapter are included in the chapter's Creative Commons licence, unless indicated otherwise in a credit line to the material. If material is not included in the chapter's Creative Commons licence and your intended use is not permitted by statutory regulation or exceeds the permitted use, you will need to obtain permission directly from the copyright holder.

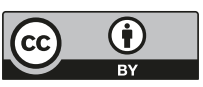

